\title{
The Effectiveness of the Combined Use of Intravenous Analgesia and Intercostal Nerve Block in Pain Control for Patients with Rib Fractures Admitted to the Emergency Service
}

\author{
(1) Eray Çınar ${ }^{1}$, (1) Anıl Gökçe ${ }^{1}$, (1) Özgür Ömer Yıldız² \\ 1Department of Thoracic Surgery, University of Health Sciences Turkey, Ankara City Hospital, Ankara, Turkey \\ 2Department of Thoracic Surgery, University of Yıldırım Beyazıt Medicine Faculty, Ankara City Hospital, Ankara, Turkey
}

\begin{abstract}
Aim: Traumatic rib fractures are a common injury in the trauma population and may cause severe pain in cases of both isolated rib fractures and chest injuries. The aim of our study was to compare the early pain control of intercostal block with that of intravenous analgesia + intercostal nerve block in patients with rib fractures admitted to the emergency department due to blunt thoracic trauma.

Materials and Methods: Patients admitted to the emergency department due to blunt thoracic trauma in a tertiary medical facility were evaluated retrospectively. Forty-eight patients were included in the study. The patients were divided into two groups: on in which only intercostal nerve block was performed and another in which intravenous analgesia + intercostal block were performed concurrently.

Results: Nine patients (18.7\%) were given only intercostal block, while 39 patients (81.3\%) were given intravenous analgesia + intercostal nerve block. Considering the early pain results of group A (intercostal nerve block) and group B (intravenous analgesia + intercostal nerve block), significant improvement was observed in group B in terms of pain results after the first 15 minutes.

Conclusion: We conclude that the combination of intravenous nonsteroidal anti-inflammatory drugs or opioid derivatives and intercostal nerve block would be an effective combination in pain control in patients with rib fractures. In addition, intercostal nerve block would be beneficial in pain control and increase respiratory efficiency in patients with rib fractures, since it is both easy to apply and accelerates healing by providing effective analgesia. Due to these positive effects, we believe that it reduces the duration of hospital stay and would offer great advantages in terms of efficiency and cost.
\end{abstract}

Keywords: Rib fracture, pain control, emergency service, intravenous analgesia + intercostal block

\section{Introduction}

Traumatic rib fractures are a common injury in the trauma population and may cause severe pain in cases of both isolated rib fractures and chest injuries $(1,2)$. Rib fractures are clinically important and even isolated fractures are associated with significant consequences such as long-term pain and disability (3). The number of rib fractures is indicative of the severity of the trauma, and $90 \%$ of patients with multiple rib fractures have injuries involving the head, abdomen, and/or extremities
(1). Multiple traumas with an increasing number of fractures, advanced age, and rib fractures are associated with increased morbidity and mortality rates $(1,4,5)$. Thoracic pain caused by rib fractures or chest contusion limits patients' coughing and deep breathing, which may cause atelectasis and pneumonia. Patients may also suffer from pulmonary contusion due to injuries and this situation may cause acute respiratory distress syndrome and/ or respiratory failure; mechanical ventilation may be needed $(6,7)$. 
A combination of adequate pain control, respiratory assistance, and physiotherapy is considered key in the management of patients with rib fractures $(4,8)$. Approaches used in treatment include epidural catheters; intravenous (patient-controlled) narcotics; intercostal, paravertebral, or interpleural blocks; oral opioids; and different analgesic treatments $(9,10)$.

The literature on the use of different analgesic treatments is insufficient. Epidural analgesia or multimodal approaches was recommended for patients with blunt chest trauma compared to opioids (9). In the systematic reviews of Duch and Møller (10) and Carrier et al. (11), it was reported that evidence for the use of epidural analgesia as the preferred method is insufficient.

However, comprehensive studies comparing modalities independently, including both observational studies and randomized controlled trials, were not analyzed. Therefore, the aim of our study was to compare the early pain control of intercostal block with that of intravenous analgesia + intercostal block in patients with rib fractures admitted to the emergency department due to blunt thoracic trauma.

\section{Materials and Methods}

Ethics committee approval of the study was obtained from the local ethics committee (Ankara City Hospital, decision no: E120-363, date: 27.02.2020). Patients admitted to the emergency department due to blunt thoracic trauma in a tertiary medical facility were retrospectively evaluated. A total of 48 patients were included in the study. The patients were divided into two groups as those receiving only intercostal block and those receiving intravenous analgesia + intercostal block. Patients were evaluated for early pain control parameters in terms of age, gender, trauma type, number of rib fractures, and method of treatment.
Patients with major trauma to the head and abdomen in addition to blunt thoracic trauma were excluded from the study. Patients with severe hemorrhagic trauma were also excluded. Patient groups were analyzed comparatively primarily in terms of age, gender, and number of rib fractures. According to the treatment method applied in both patient groups, results were compared according to pain levels at $0^{\text {th }}, 15^{\text {th }}, 30^{\text {th }}$, and $120^{\text {th }}$ minutes.

\section{Statistical Analysis}

The chi-square test or Fisher's exact test was used to show the relationships between categorical data and demographic and clinical data of patients and descriptive statistics. Student's t-test and Mann-Whitney $\mathrm{U}$ analysis were used for continuous variables. Values of $p<0.05$ were considered significant in the study. SPSS 22 (IBM Corp., Armonk, NY, USA) was used for calculations.

\section{Results}

Of the 48 patients included in the study, 30 (62.5\%) were male and 18 (37.5\%) were female. The mean age was 46.08 \pm 20.01 years (range: 15-91). Thirty-seven patients were under 65 years of age, while 11 patients were 65 years of age or older. Eighteen (37.5\%) patients had experienced traffic accidents, 11 (22.9\%) assault, 14 (29.2\%) falling, 2 (4.2\%) rib fractures due to animal attacks, and 3 (6.3\%) motorcycle accidents. Twenty-two patients (45.8\%) had fractures on the right side and 26 patients (54.2\%) on the left side. Nine patients (18.7\%) were administered only intercostal block, while 39 patients (81.3\%) were administered intravenous analgesia + intercostal block (Table 1).

The patient groups were compared according to the pain levels at $0^{\text {th }}, 15^{\text {th }}, 30^{\text {th }}$, and $120^{\text {th }}$ minutes according to the treatment method applied, including only intercostal block and intravenous analgesia + intercostal block. Considering the early pain results of group A and group B, a significant improvement was observed in Group $B$ in terms of pain results after the first 15 minutes $(p<0.05)$ (Table 2)

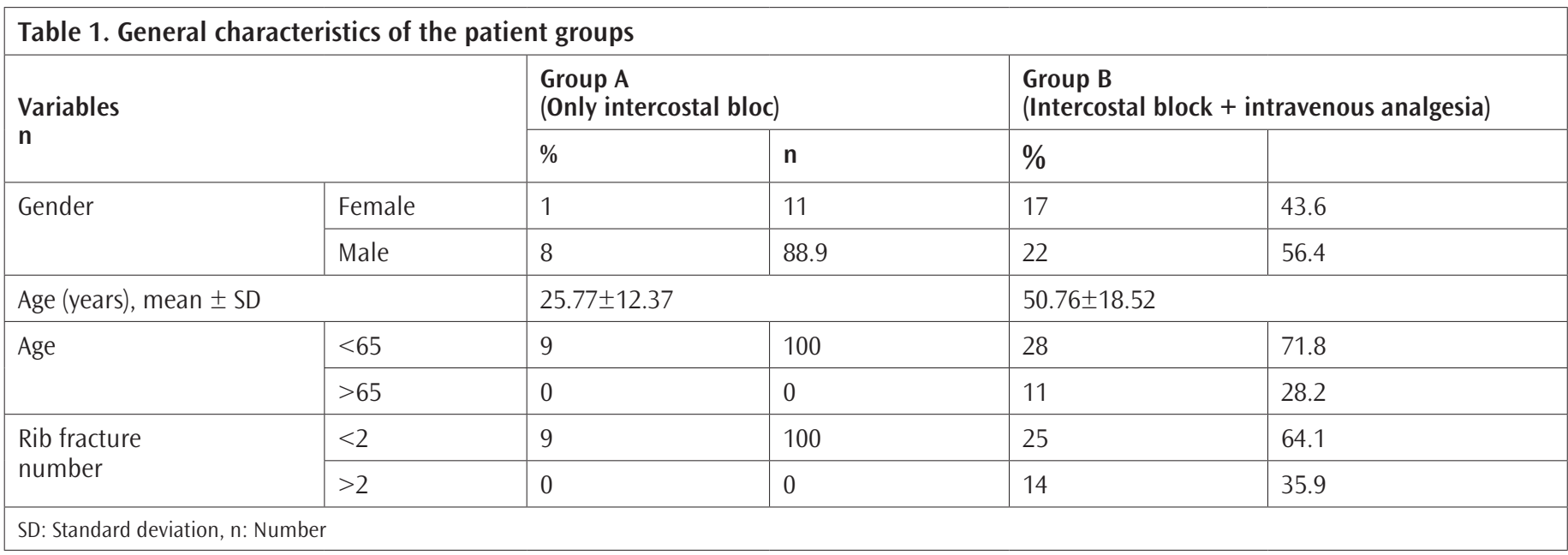




\section{Discussion}

The most important problem of rib fractures is pain. It is known that pain causes ineffective coughing, atelectasis with a decrease in the depth of respiratory capacity, hypoxemia, postoperative lung infection, and many other complications such as respiratory distress. These complications increase with age, smoking, obesity, and additional diseases. For this reason, various methods such as intravenous analgesia, intercostal block, epidural analgesia, and patient-controlled analgesia are used in pain control $(12,13)$.

Intravenous narcotic analgesia is one of the most commonly used treatment modalities in patients with chest trauma. Patient comfort and treatment of respiratory depression should be carefully considered, especially in elderly patients (14). In the study of Bayouth et al. (15), it was noted that intravenous treatment with NSAI medications was very effective in reducing pain in patients with rib fractures. In the study of Kieninger et al. (16), it was reported that intravenous analgesic treatment was a more effective and reliable method with a low complication rate compared to epidural pain control.
One of the most effective methods of relieving acute pain is local anesthesia. Intercostal block is a simple and effective method that provides analgesia after upper abdominal and thoracic surgery. With this method, adequate analgesia may be provided and the ability to cough and breathe deeply may be increased. It is especially useful in the early stages of trauma and provides eight hours of analgesia. Since the drugs are used locally, the rates of side effects and morbidity are very low. In some articles, it has been stated that intercostal blocks provide pain control close to that of thoracic epidural analgesia (17). In the study of Sheets et al. (18), where intercostal nerve block was compared with epidural analgesia, the pain scores were the same in the two groups and the incidence of side effects was higher in the epidural analgesia group. In the study of Osinowo et al. (19), it was stated that intercostal block with $0.5 \%$ bupivacaine was very effective in pain control in patients with rib fractures and it may be applied safely. In the studies of Hwang and Lee (20) and Britt et al. (21), the intercostal block method applied for pain control in cases of rib fractures caused by blunt thoracic trauma increased the respiratory efficiency of the patients and significantly

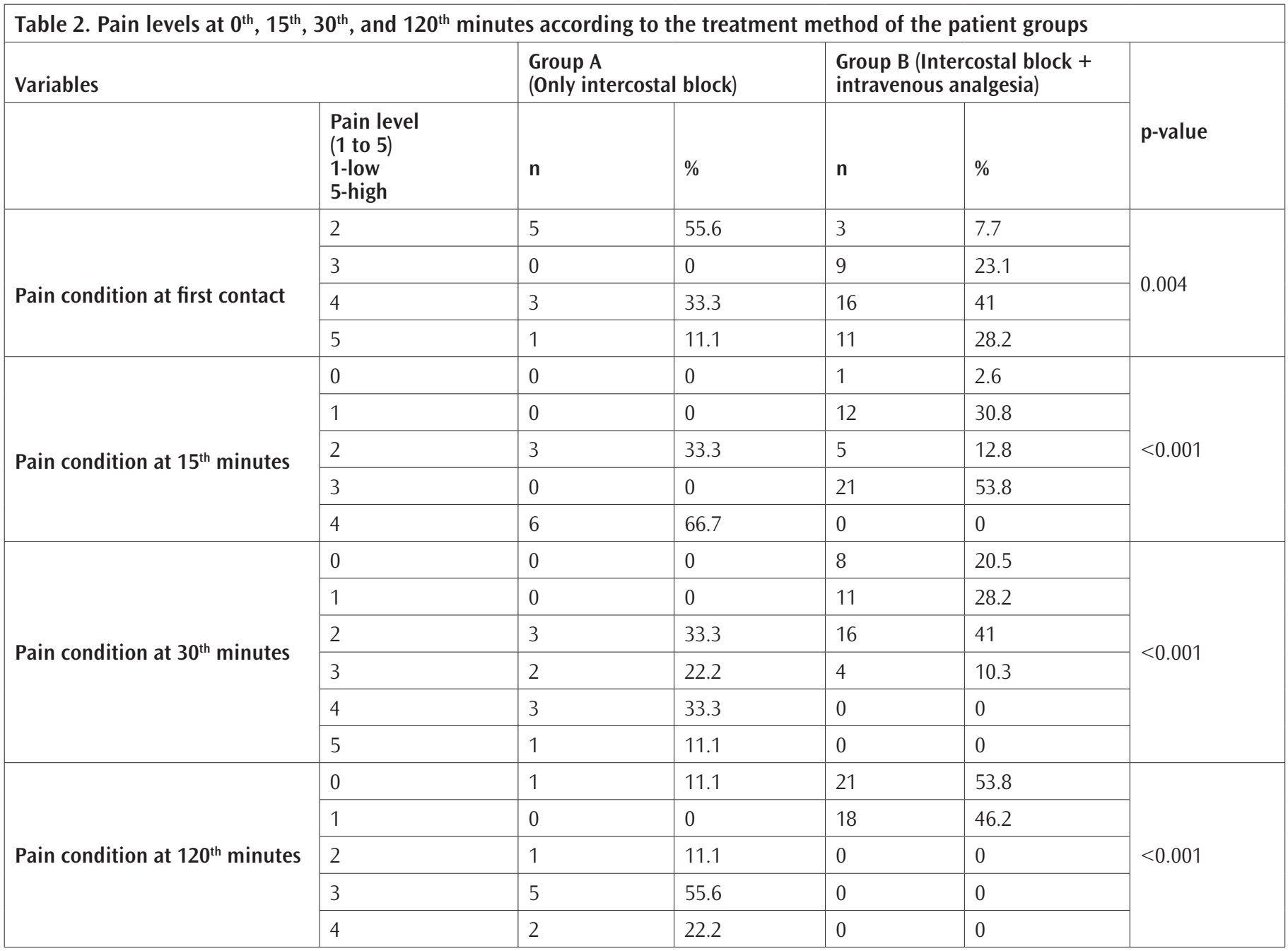


reduced the duration of hospital stay. In our study, considering the early pain results of the group with only intercostal block and the group with intercostal block + intravenous analgesia, a significant improvement was observed in the intercostal block + intravenous analgesia group in terms of pain results after the first 15 minutes $(p<0.05)$. For this reason, we concluded that the combined use of intravenous analgesia and intercostal block is more effective than other methods in pain control.

\section{Study Limitations}

The main limitation of the study that it was retrospective, the number of patients was insufficient. It could have been done by more than one center.

\section{Conclusion}

In our study, we found that the combination of intravenous NSAIDs or opioid derivatives and intercostal nerve block is an effective combination in pain control in patients with rib fractures. In addition, we think that intercostal nerve block will be beneficial in pain control and increase respiratory efficiency in patients with rib fractures, since it is both easy to apply and accelerates healing by providing effective analgesia. Due to these positive effects, we think that it may reduce the duration of hospital stay and be very beneficial in terms of efficiency and cost.

\section{Ethics}

Ethics Committee Approval: This study was approved by the Ethics Committee of Ankara City Hospital, decision no: E1-20363, date: 27.02 .2020 .

Informed Consent: Retrospective study.

Peer-review: Externally peer-reviewed.

\section{Authorship Contributions}

Concept: E.Ç., A.G., Ö.Ö.Y., Design: E.Ç., A.G., Ö.Ö.Y., Data Collection or Processing: E.C.., A.G., Ö.Ö.Y., Analysis or Interpretation: E.C.., A.G., Ö.Ö.Y., Literature Search: E.Ç., A.G., Ö.Ö.Y., Writing: E.C.., A.G., Ö.Ö.Y.

Conflict of Interest: No conflict of interest was declared by the authors.

Financial Disclosure: The authors declared that this study received no financial support.

\section{References}

1. Ziegler DW, Agarwal NN. The morbidity and mortality of rib fractures. J Trauma. 1994;37:975-9.

2. Shorr RM, Rodriguez A, Indeck MC, Crittenden MD, Hartunian S, Cowley RA. Blunt chest trauma in the elderly. J Trauma. 1989;29:234-7.
3. Cinar E, Yildiz 00, Aytekin Celik I, Gungorer B, Usul E, Yorulmaz S, et al. Retrospective analysis of thoracic trauma and evaluation of the factors affecting the duration of stay in the hospital. Disaster Emerg Med J. 2020;5:159-63.

4. Bulger EM, Arneson MA, Mock CN, Jurkovich GJ. Rib fractures in the elderly. J Trauma. 2000;48:1040-6.

5. Holcomb JB, McMullin NR, Kozar RA, Lygas MH, Moore FA. Morbidity from rib fractures increases after age 45. J Am Coll Surg. 2003;196:549-55.

6. Mohta M, Verma P, Saxena AK, Sethi AK, Tyagi A, Girotra G. Prospective, randomized comparison of continuous thoracic epidural and thoracic paravertebral infusion in patients with unilateral multiple fractured ribs--a pilot study. J Trauma. 2009;66:1096-101.

7. Sirmali M, Türüt H, Topçu S, Gülhan E, Yazici U, Kaya S, et al. A comprehensive analysis of traumatic rib fractures: morbidity, mortality and management. Eur J Cardiothorac Surg. 2003;24:133-8.

8. Bulger EM, Edwards T, Klotz P, Jurkovich GJ. Epidural analgesia improves outcome after multiple rib fractures. Surgery. 2004;136:426-30.

9. Galvagno SM Jr, Smith CE, Varon AJ, Hasenboehler EA, Sultan S, Shaefer G, et al. Pain management for blunt thoracic trauma: A joint practice management guideline from the Eastern Association for the Surgery of Trauma and Trauma Anesthesiology Society. J Trauma Acute Care Surg. 2016;81:936-51.

10. Duch P, Møller MH. Epidural analgesia in patients with traumatic rib fractures: a systematic review of randomised controlled trials. Acta Anaesthesiol Scand. 2015;59:698-709.

11. Carrier FM, Turgeon AF, Nicole PC, Trépanier CA, Fergusson DA, Thauvette D, et al. Effect of epidural analgesia in patients with traumatic rib fractures: a systematic review and meta-analysis of randomized controlled trials. Can J Anaesth. 2009;56:230-42.

12. Logas WG, el-Baz N, el-Ganzouri A, Cullen M, Staren E, Faber LP, et al. Continuous thoracic epidural analgesia for postoperative pain relief following thoracotomy: a randomized prospective study. Anesthesiology. 1987;67:787-91.

13. Takamori S, Yoshida S, Hayashi A, Matsuo T, Mitsuoka M, Shirouzu K. Intraoperative intercostal nerve blockade for postthoracotomy pain. Ann Thorac Surg. 2002;74:338-41.

14. Yüksel M, Çetin G, editörler. Toraks travmaları. İstanbul: Turgut Yayıncılık; 2003.

15. Bayouth L, Safcsak K, Cheatham ML, Smith CP, Birrer KL, Promes JT. Early intravenous ibuprofen decreases narcotic requirement and length of stay after traumatic rib fracture. Am Surg. 2013;79:1207-12.

16. Kieninger AN, Bair HA, Bendick PJ, Howells GA. Epidural versus intravenous pain control in elderly patients with rib fractures. Am J Surg. 2005;189:32730

17. Concha M, Dagnino J, Cariaga M, Aguilera J, Aparicio R, Guerrero M. Analgesia after thoracotomy: epidural fentanyl/bupivacaine compared with intercostal nerve block plus intravenous morphine. J Cardiothorac Vasc Anesth. 2004;18:322-6.

18. Sheets NW, Davis JW, Dirks RC, Pang AW, Kwok AM, Wolfe MM, et al Intercostal Nerve Block with Liposomal Bupivacaine vs Epidural Analgesia for the Treatment of Traumatic Rib Fracture. J Am Coll Surg. 2020;231:150-4.

19. Osinowo OA, Zahrani M, Softah A. Effect of intercostal nerve block with $0.5 \%$ bupivacaine on peak expiratory flow rate and arterial oxygen saturation in rib fractures. J Trauma. 2004;56:345-7.

20. Hwang EG, Lee Y. Effectiveness of intercostal nerve block for management of pain in rib fracture patients. J Exerc Rehabil. 2014;10:241-4.

21. Britt T, Sturm R, Ricardi R, Labond V. Comparative evaluation of continuous intercostal nerve block or epidural analgesia on the rate of respiratory complications, intensive care unit, and hospital stay following traumatic rib fractures: a retrospective review. Local Reg Anesth. 2015;8:79-84. 